\title{
Prevalence of human norovirus and Clostridium difficile coinfections in adult hospitalized patients
}

\author{
Janelle N Stokely' \\ Sandra Niendorf ${ }^{2}$ \\ Stefan Taube' \\ Marina Hoehne ${ }^{2}$ \\ Vincent B Young 1,3 \\ Mary AM Rogers ${ }^{4}$ \\ Christiane E Wobus' \\ 'Department of Microbiology and \\ Immunology, University of Michigan \\ Medical School, Ann Arbor, MI, \\ USA; ${ }^{2}$ Department of Infectious \\ Diseases, Consultant Laboratory for \\ Noroviruses, Robert Koch Institute, \\ Berlin, Germany; ${ }^{3}$ Department \\ of Internal Medicine, Division of \\ Infectious Diseases, ${ }^{4}$ Department of \\ Internal Medicine, Division of General \\ Medicine, University of Michigan \\ Medical School, Ann Arbor, MI, USA
}

Correspondence: Mary AM Rogers Department of Internal Medicine, Division of General Medicine, University of Michigan Medical School, NCRC, 2800 Plymouth Rd, Bldg 16/440E, Ann Arbor, MI 48I09-2800, USA

Email maryroge@umich.edu

Christiane E Wobus

Department of Microbiology and Immunology, University of Michigan Medical School, I I 50 West Medical Center Dr., 5737 MSII, Ann Arbor, MI 48109, USA

Email cwobus@umich.edu

\author{
This article was published in the following Dove Press journal: \\ Clinical Epidemiology \\ 28 June 2016 \\ Number of times this article has been viewed
}

\begin{abstract}
Objective: Human norovirus $(\mathrm{HuNoV})$ and Clostridium difficile are common causes of infectious gastroenteritis in adults in the US. However, limited information is available regarding $\mathrm{HuNoV}$ and $C$. difficile coinfections. Our study was designed to evaluate the prevalence of $\mathrm{HuNoV}$ and $C$. difficile coinfections among adult patients in a hospital setting and disease symptomatology.
\end{abstract}

Study design and setting: For a cross-sectional analysis, 384 fecal samples were tested for the presence of $C$. difficile toxins from patients $(\mathrm{n}=290)$, whom the provider suspected of $C$. difficile infections. Subsequent testing was then performed for HuNoV genogroups I and II. Multinomial logistic regression was performed to determine symptoms more frequently associated with coinfections.

Results: The final cohort consisted of the following outcome groups: $C$. difficile ( $\mathrm{n}=196), C$. difficile + HuNoV coinfection $(n=40)$, HuNoV only $(n=12)$, and neither $(n=136)$. Coinfected patients were more likely to develop nausea, gas, and abdominal pain and were more likely to seek treatment in the winter season compared with individuals not infected or infected with either pathogen alone.

Conclusion: Our study revealed that patients with coinfection are more likely to experience certain gastrointestinal symptoms, in particular abdominal pain, suggesting an increased severity of disease symptomatology in coinfected patients.

Keywords: human norovirus, C. difficile, gastroenteritis, coinfection

\section{What is new?}

- The key findings are that 1) human norovirus (HuNoV) and Clostridium difficile coinfections are relatively frequent, 2) coinfected patients are more likely to develop nausea, gas, and abdominal pain, and 3 ) they are more likely to reside in a communal setting than those not infected.

- The increased number of follow-up visits associated with HuNoV and C. difficile coinfections suggests an increased severity of gastrointestinal disease symptomatology in coinfected patients.

- A greater awareness of the high frequency of $\mathrm{HuNoV} / C$. difficile coinfections, particularly in communal settings, may improve patient management and infection control. 


\section{Introduction}

Acute gastroenteritis (AGE), defined as diarrheal disease of rapid onset potentially accompanied by nausea, vomiting, fever, or abdominal pain, is a major cause of illness in the US resulting in $\sim 179$ million episodes of AGE each year. ${ }^{1}$ Human norovirus (HuNoV) is the leading cause of AGE outbreaks in the US. ${ }^{1}$ In addition, AGE is also an important cause of mortality worldwide, especially in children. ${ }^{2}$ In the US, the number of people, mostly elderly, who have suffered a gastroenteritis-related death has doubled during the last decade with Clostridium difficile representing the main and HuNoV the second leading infectious causes. ${ }^{3}$

C. difficile is a Gram-positive, spore-forming, and toxinproducing bacterium. It is the most common cause of health care-associated infectious gastroenteritis in the US, causing $\sim 3$ million infections yearly that result in a significant burden of diarrhea and colitis per year. ${ }^{4}$ Over the past decade, the incidence and severity of $C$. difficile infections (CDIs) has been increasing. ${ }^{5} \mathrm{C}$. difficile invades the disrupted intestinal microbiota following antibiotic treatment, and pathogenesis is mainly attributed to the two predominant toxins, TcdA and TcdB. Treatment of CDI includes antibiotic discontinuation, administration of specific antibiotics, such as metronidazole or vancomycin, or in severe cases, fecal transplants. ${ }^{5}$ However, colonization does not always result in active infection and a proportion of those exposed become asymptomatic carriers.

HuNoVs are nonenveloped, single-stranded, positivesense ribonucleic acid (RNA) viruses that cause $\sim 20 \%$ of all cases of AGE worldwide. ${ }^{6}$ In the US alone, these viruses cause $\sim 21$ million infections each year. ${ }^{7}$ Approximately 5.5 million cases, over half ( $58 \%$ ) of all food-borne infections are caused by HuNoVs, ${ }^{8}$ which cost an estimated $\sim$ US\$ 5.8 billion. ${ }^{9}$ Noroviruses are divided into at least seven genogroups (G), three of which infect humans (GI, GII, and GIV).${ }^{10}$ Genogroup II genotype 4 (GII.4) noroviruses are the most prevalent and clinically significant HuNoVs, causing approximately two-thirds of all outbreaks. ${ }^{11}$ Although, GII.17 strains are emerging and increasing in prevalence. ${ }^{12}$ HuNoV symptoms include vomiting and diarrhea, which are rapid in onset but usually resolve in $12-60$ hours. ${ }^{13}$ Virions are expelled in vomitus and/or feces of symptomatic and asymptomatic carriers for transmission by the fecal-oral route. ${ }^{14}$ There are currently no specific treatments approved for $\mathrm{HuNoV}$ infections aside from supportive care. ${ }^{15}$

Despite their health importance, little is known about the association between $C$. difficile and HuNoVs in the host. Although coinfections with both pathogens have been reported, the cohorts were very limited in number. ${ }^{16-18}$ Both pathogens have been mistaken as an infectious cause for the other ${ }^{19}$ because these pathogens share similar symptoms (primarily diarrhea, nausea, abdominal pain, and fever). One study postulated an antagonistic relationship between the two pathogens, in that the pathogens compete against one another and limit the other's pathogenicity. ${ }^{17}$ However, the risk factors and clinical features associated with coinfections are not well understood. Therefore, the aim of our study was to assess the prevalence of coinfection in a cohort of patients with gastroenteritis, and to examine the symptomatology and characteristics of those coinfected with $C$. difficile and HuNoV. Findings reported herein may help with the clinical management of patients with gastrointestinal symptoms, as well as infection control and prevention.

\section{Methods Study population}

The study population has been previously described. ${ }^{20} \mathrm{~A}$ cross-sectional study was conducted at the University of Michigan Health System (UMHS, Ann Arbor, MI, USA), following approval by the Institutional Review Board at the University of Michigan. Symptoms were determined from individual retrospective patient data questionnaires and electronic patient records from UMHS at any time prior to diagnosis of CDI and written informed consent was received from all patients from October 2010 to August 2013. All subjects were adults (18 years and older), who had been admitted for treatment at UMHS and the provider suspected CDI. CDI testing is ordered for symptomatic patients; for example, those with antibiotic-associated diarrhea. For the purpose of this analysis, individuals who were discharged and sought treatment again at least 2 weeks after the initial treatment and hospital discharge were considered reinfected and analyzed separately. For individuals with multiple $C$. difficile test samples, the first test result and sample was used in this study. Controls were patients who tested negative for CDI.

\section{Stool collection and handling}

Stools samples from hospitalized inpatients and ambulatory outpatients presenting to the main hospital or UMHS offsite facilities were obtained, stored in Cary-Blair transport media and tested for $C$. difficile as described. ${ }^{20}$ Specifically, clinician-ordered stool specimens were tested for the presence of $C$. difficile glutamate dehydrogenase antigen and toxins A and B using the C. DIFFICILE QUIK CHEK COMPLETE ${ }^{\circledR}$ test (Techlab, Inc., Blacksburg, VA, USA). All antigen/toxin 
discordant stool tests were subjected to analysis for the $t c d B$ gene by real-time polymerase chain reaction (PCR) (BD GeneOhm $^{\text {TM }}$ Cdiff Assay; Franklin Lakes, NJ, USA). C. difficile presence was confirmed by growth on taurocholatecycloserine cefoxitin fructose agar plates and brain heart infusion-supplemented tubes at $37^{\circ} \mathrm{C}$ as described. ${ }^{21}$ Remaining stool samples were aliquoted and stored at $-80^{\circ} \mathrm{C}$.

\section{HuNoV testing}

To test for the presence of HuNoV, viral RNA was extracted from stool samples using the QIAamp Viral RNA Mini Kit (Qiagen, Redwood City, CA, USA) according to the manufacturer's protocol. RNA was further cleaned up with the TURBO DNA-free Ambion RNA kit (Thermo Fisher Scientific, Waltham, MA, USA) following the manufacturer's recommendations.

Samples were first screened for GII HuNoV by TaqMan quantitative reverse transcription-PCR using CFX96 Real Time System (Thermo Fisher Scientific). Oligonucleotide primers and probe specific for the junction between ORF1 and ORF2 of the HuNoV genome were previously described. ${ }^{22}$ A $20 \mu \mathrm{L}$ PCR reaction was performed using iScript onestep quantitative reverse transcription-PCR kit (Bio-Rad Laboratories Inc., Hercules, CA, USA) with the following conditions: $50^{\circ} \mathrm{C}(10$ minutes $), 95^{\circ} \mathrm{C}(5$ minutes $) ; 40$ cycles at $94^{\circ} \mathrm{C}$ (10 seconds) and at $60^{\circ} \mathrm{C}(30$ seconds). Standard curves were generated from ten-fold dilutions of plasmid pSCGII in each run. The pSC-GII plasmid was constructed by amplifying $93 \mathrm{nt}$ from the ORF1/2 junction of GII.4 HuNoV MD145-12 (nt 5007 to 5099, accession number AY032605, a kind gift from K. Green, National Institutes of Health) using the forward primer: AGCCAATGTTCAGATGGATG and reverse primer: TCGACGCCATCTTCATTCAC. The segment was cloned into vector $\mathrm{pSC}-\mathrm{A}$-amp/kan using the StrataClone PCR cloning system according to the manufacturer's recommendations. A HuNoV-positive stool sample and sterile water were used in each run as positive and negative controls, respectively.

$\mathrm{HuNoV}$ samples were sequenced retrospectively after several years of storage and at least two freeze/thaw cycles. Samples were first analyzed by real-time $\mathrm{PCR}^{22}$ and RT-nested PCR in the RNA-dependent RNA polymerase gene and the junction of the $3^{\prime}$ end of ORF1 and 5' end of the ORF2 was used (region $\mathrm{A}$ and region $\mathrm{B} / \mathrm{C}$ according to Vinje et $\mathrm{al}^{23}$ ). Sample processing, amplification, and sequencing were then performed as described previously. ${ }^{24,25}$ Amplicons of both gene regions were added to the sequencing reactions using the amplification primers, the BigDye terminator v3.1 cycle sequencing kit, and an ABI 3130xI Genetic Analyzer (Applied Biosystems). Sequences were aligned to prototype sequences drawn from GenBank and phylogenetic analysis was performed using BioEdit (Version 7.2.5), ${ }^{26}$ including CLUSTAL W (Version 1.81) ${ }^{27}$ and the PHYLogeny Inference Package (Version 3.6). ${ }^{28}$

\section{Determining a detection cutoff for HuNoV-positive samples}

Following quantitative PCR for HuNoV, all cycle threshold (CT) values were graphed. Similar to the study by Trang et al, ${ }^{29}$ we observed a biphasic distribution (data not shown). CT values in one group ranged from 25 to 34 , while those in the second group ranged from 35 to 38 . To decrease the potential of false positives, a CT value of 34 was chosen as a cutoff for $\mathrm{HuNoV}$ detection. Thus in this study, samples with CT values $\leq 34$ were considered HuNoV positive, while samples with a CT value $>34$ were considered $\mathrm{HuNoV}$ negative.

\section{Clinical epidemiology}

Symptomatology, epidemiologic, and laboratory factors were analyzed to determine if certain variables were predictive of coinfection in comparison to infection with one pathogen. Epidemiologic factors included patient age, sex, race, weight, residence when sampled, and season of diagnosis as well as number of follow-up visits, use of a feeding tube, antibiotic usage within the past 7 days, and history of chronic conditions (defined as history of either cardiac disease, lung disease, kidney disease, diabetes, autoimmune disease, inflammatory bowel disease, and/or acquired immunodeficiency syndrome/ human immunodeficiency syndrome). Symptomatic factors included vomiting, nausea, abdominal pain, urgency, and gas.

\section{Data analysis}

For statistical analysis, stool samples were categorized as coinfection, HuNoV only, C. difficile only, or neither based on laboratory results. A data set of 384 stool samples from 290 patients was used for unadjusted and adjusted analysis. Statistical analyses were performed using SAS/STAT software, Version 9.3 of the SAS System for Windows (SAS Institute Inc., Cary, NC, USA) and Stata MP 14.0 (StataCorp LP, College Station, TX, USA). A two-tailed $P$-value of $<0.05$ was considered to be significant. The patient characteristics of age, sex, race, weight, residence, and previous conditions were noted at the time of study entry. Pearson's chi-squared test was used for categorical variables and one-way analysis of variance for continuous variables. For antibiotic use in the past 7 days, use of feeding tube, and season (December 
through February vs other months) when sample was submitted, a multinomial logistic regression model was used to evaluate the association with infection outcomes, accounting for the clustering within individuals. Likewise, multinomial logistic regression (clustered by patient) was used to calculate odds ratios (ORs) and $P$-values for the association between symptoms and infection outcomes (ie, coinfection, norovirus only, $C$. difficile only, or neither infection) with adjustment for patient characteristics. Neither infection was used as the reference category. All ORs were adjusted for age, sex, and repeated sample collection after 2 weeks.

\section{Results}

\section{HuNoV screening of study cohort}

To determine the level of coinfection between $C$. difficile and $\mathrm{HuNoV}$, we screened 384 stool samples from 290 UMHS patients for the presence of HuNoV. The age (mean \pm standard deviation) of all patients at the time of study entry was 56.2 years ( \pm 16.4 years) and $44 \%$ were male. Of the 384 stool samples collected, 236 samples were positive for $C$. difficile, while 148 samples tested negative for $C$. difficile. Of the positive $C$. difficile samples, 40 also tested positive for $\mathrm{HuNoV}(17 \%)$. Of the 148 negative $C$. difficile samples, 12 tested positive for $\mathrm{HuNoV}(8 \%)$. A total of ten HuNoV samples were successfully sequenced. Genotyping of nine samples indicated GII.P4/GII.4 2009 HuNoV strains, while one sample contained GII.Pg/GII.1 HuNoV. Fecal samples from 125 patients tested negative for either pathogen and were used as controls. Taken together, the final cohort had the following outcome groups: $C$. difficile only ( $\mathrm{n}=196$ specimens, 131 patients), C. difficile + HuNoV ( $n=40$ specimens, 24 patients), HuNoV only ( $n=12$ specimens, ten patients), and neither ( $n=136$ specimens, 125 patients).

Age, sex, race, and weight were similar across the four outcome groups at the time of enrollment (Table 1). However, there was a difference in infection depending upon where the patient resided $(P=0.0004)$. For those with a coinfection, $21 \%$ lived in a rehabilitation center, nursing home, assisted living center, or dormitory, while only $3 \%$ of the controls lived in such residences. When included in a multinomial logit model (accounting for clustering), the difference between coinfection (specifically) and controls was significant for residential living $(P<0.001)$. There was also a significant difference in residences for those with $C$. difficile and controls $(P=0.014)$; $11 \%$ of those with $C$. difficile resided in communal residences compared with $3 \%$ of the controls. In addition, no significant difference was observed in infections in the winter season
Table I Characteristics of patients by infection status

\begin{tabular}{|c|c|c|c|c|}
\hline Characteristics & Coinfection & Norovirus & $\begin{array}{l}\text { Clostridium } \\
\text { difficile }\end{array}$ & Neither \\
\hline Age, mean (SD) & $60.2(16.1)$ & $58.4(11.8)$ & $54.8(18.3)$ & $56.7(14.6)$ \\
\hline Female, $\mathrm{n}(\%)$ & $14(58)$ & $5(50)$ & $68(52)$ & $74(59)$ \\
\hline $\begin{array}{l}\text { Race (White), } \\
\text { n (\%) }\end{array}$ & $22(96)$ & $7(78)$ & II4 (9I) & $110(91)$ \\
\hline \multicolumn{5}{|l|}{$\begin{array}{l}\text { Weight (Ib), } \\
\text { mean (SD) }\end{array}$} \\
\hline Female & $149(50)$ & $174(68)$ & $164(53)$ & $168(65)$ \\
\hline Male & $|8|(55)$ & $226(27)$ & $183(54)$ & $199(53)$ \\
\hline \multicolumn{5}{|l|}{ Residence, n (\%) } \\
\hline Single family & $19(79)$ & $9(90)$ & II 6 (89) & $12 \mid(97)$ \\
\hline Multiple $^{\mathrm{a}}$ & $5(2 I)$ & $I(10)$ & $14(\mathrm{II})$ & $4(3)$ \\
\hline $\begin{array}{l}\text { Previous } \\
\text { conditions }{ }^{\mathrm{b}}, \mathrm{n}(\%)\end{array}$ & $18(75)$ & $7(70)$ & $73(56)$ & $87(70)$ \\
\hline Winterc, $^{c}$ (\%) & $19(47)$ & $4(33)$ & $56(29)$ & $36(26)$ \\
\hline $\begin{array}{l}\text { Feeding tube, } \\
\mathrm{n}(\%)\end{array}$ & $9(22)$ & $\mathrm{I}(8)$ & $37(19)$ & $29(2 \mathrm{I})$ \\
\hline $\begin{array}{l}\text { Antibiotics in } \\
\text { past } 7 \text { days, } n(\%)\end{array}$ & $33(82)$ & $10(83)$ & $176(90)$ & $109(0)$ \\
\hline
\end{tabular}

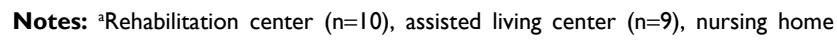
$(n=3)$, dormitory $(n=I)$, other $(n=I)$. bHeart disease, lung disease, kidney disease, diabetes, autoimmune disease, inflammatory bowel disease, and/or AIDS/HIV. cSample collected in December through February.

$(P=0.090)$ across all groups. However, a direct comparison of coinfection versus control (47\% of coinfections occurred in the winter compared with $26 \%$ for controls) within a multinomial logit model demonstrated significance $(P=0.017)$. Analysis of recent antibiotic use indicated no difference across all four outcome groups combined; although when patients with $C$. difficile were directly compared with controls in the multinomial logit model, the difference was significant $(P=0.015)$.

Clinical symptoms of vomiting $(P=0.013)$, nausea $(P=0.002)$, and abdominal pain $(P=0.012)$ showed significant difference among outcomes, while no differences were observed for the symptoms of gastrointestinal urgency $(P=0.920)$ or gas $(P=0.650)$ (Table 2$)$. Nausea and vomiting were particularly present in patients with $\mathrm{HuNoV}(75 \%)$ (Figure 1). Vomiting symptoms were typically combined with nausea and few to no patients presented with vomiting only (Figure 1). Furthermore, abdominal pain was the symptom that best differentiated those patients with a coinfection as abdominal pain occurred in $70 \%$ of those with a coinfection compared with $57 \%$ in controls $(P=0.002)$ (Table 2$)$. No significant difference in abdominal pain was observed between patients with $C$. difficile-only infections and hospitalized controls.

To identify clinical symptoms and characteristics that differentiated coinfected patients from the other outcome 
Table 2 Clinical symptoms of patients by infection status at time of sample collection

\begin{tabular}{|c|c|c|c|c|}
\hline Characteristic & $\begin{array}{l}\text { Coinfection } \\
(n=40)\end{array}$ & $\begin{array}{l}\text { Norovirus } \\
\text { only } \\
(n=12)\end{array}$ & $\begin{array}{l}\text { Clostridium } \\
\text { difficile only } \\
(n=196)\end{array}$ & $\begin{array}{l}\text { Neither } \\
(n=136)\end{array}$ \\
\hline \multicolumn{5}{|l|}{ Vomiting (\%) } \\
\hline Yes & $16(40)$ & $9(75)$ & $74(38)$ & $38(28)$ \\
\hline No & $24(60)$ & $3(25)$ & $122(62)$ & $98(72)$ \\
\hline \multicolumn{5}{|l|}{ Nausea (\%) } \\
\hline Yes & $27(68)$ & $10(83)$ & $109(44)$ & $57(42)$ \\
\hline No & $13(32)$ & $2(17)$ & $87(56)$ & $79(58)$ \\
\hline \multicolumn{5}{|l|}{ Abdominal } \\
\hline \multicolumn{5}{|l|}{ pain (\%) } \\
\hline Yes & $28(70)$ & $8(67)$ & $104(53)$ & $77(57)$ \\
\hline No & $12(30)$ & $4(33)$ & $92(47)$ & $59(43)$ \\
\hline \multicolumn{5}{|l|}{$\begin{array}{l}\text { Gastrointestinal } \\
\text { urgency (\%) }\end{array}$} \\
\hline Yes & $24(62)$ & $7(58)$ & $112(57)$ & $82(6 I)$ \\
\hline No & $15(38)$ & $5(42)$ & $84(43)$ & $53(39)$ \\
\hline \multicolumn{5}{|l|}{ Gas (\%) } \\
\hline Yes & $26(65)$ & $6(50)$ & $117(60)$ & $76(56)$ \\
\hline No & $14(35)$ & $6(50)$ & $78(40)$ & $60(44)$ \\
\hline
\end{tabular}

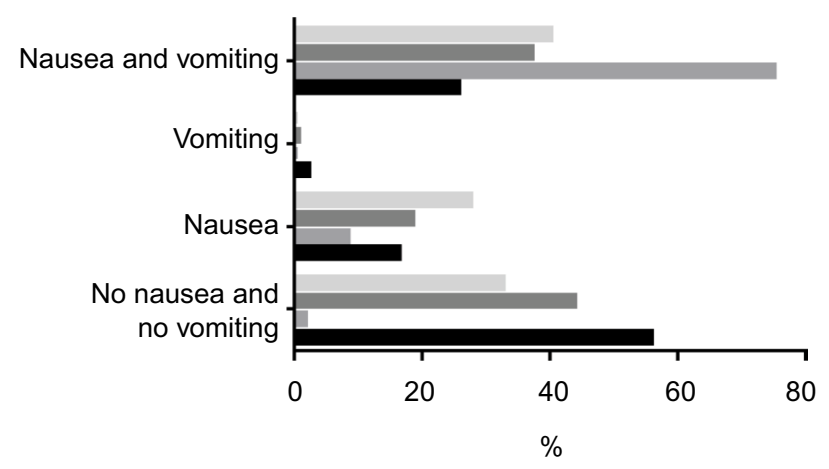

\begin{tabular}{l|l} 
Neither & C. difficile only \\
Norovirus only & Coinfection
\end{tabular}

Figure I Differences in nausea and vomiting by type of infection.

Note: The percentage of patients in each outcome group was graphed according to symptoms: vomiting only, nausea only, neither, or both. groups with adjustment for demographic characteristics, repeated sampling (after 2 weeks post original sample), and using a quantitative PCR CT cutoff of 34 for HuNoV, there was a significant interaction between nausea and vomiting and infection status (Table 3). Coinfection was more likely in patients who presented with abdominal pain $(\mathrm{OR}=4.77,95 \%$ confidence interval [CI]: 2.09-10.9]), nausea (OR $=4.30$, 95\% CI: $1.65-11.3$ ), gas ( $\mathrm{OR}=2.30,95 \%$ CI: $1.03-5.10)$, or had a diagnosis during the winter season (December-February) $(\mathrm{OR}=2.30,95 \% \mathrm{CI}: 1.0-4.82)$. Patients with $C$. difficileonly infection also had significant nausea and abdominal pain $(\mathrm{OR}=1.94,95 \% \mathrm{CI}: 1.04-3.60$ and $\mathrm{OR}=1.70,95 \%$ CI: $1.06-2.73$, respectively). The ORs were greater in coinfected patients compared with $C$. difficile-only infection suggesting a greater prevalence of nausea and abdominal pain in the coinfected group. When coinfection was directly compared with $C$. difficile only, abdominal pain remained more prevalent in those with coinfection $(\mathrm{OR}=2.10,95 \%$ CI: $1.11-3.98, P=0.023)$. In addition, follow-up visits were greater in coinfection versus $C$. difficile only $(P=0.042)$. Those with HuNoV-only infections were significantly more likely to experience vomiting ( $\mathrm{OR}=5.47,95 \% \mathrm{CI}$ : 0.85-34.8) compared with coinfected and C. difficile-only infected patients, who showed no significant association for vomiting as a symptom ( $\mathrm{OR}=1.02,95 \% \mathrm{CI}$ : $0.40-2.63$ and $\mathrm{OR}=1.21,95 \%$ CI: $0.63-2.35$, respectively). As expected, patients with $C$. difficile-only infection showed a 2.89 greater odds (95\% CI: 1.47-5.69) of having used antibiotics in the 7 days prior to sampling $(P=0.002)$. Taken together, these data indicate that coinfected patients were more likely to develop nausea, gas, and abdominal pain, and were more likely to seek treatment in the winter season compared with those infected with either pathogen alone.

Table 3 Adjusted ORs for disease outcome using multinomial logistic regression ${ }^{\mathrm{a}}$

\begin{tabular}{|c|c|c|c|c|c|c|c|c|c|}
\hline \multirow[t]{2}{*}{ Disease outcome } & \multicolumn{3}{|c|}{ Coinfection } & \multicolumn{3}{|c|}{ Norovirus only } & \multicolumn{3}{|c|}{ Clostridium difficile only } \\
\hline & OR & $95 \% \mathrm{Cl}$ & $P$-value & OR & $95 \% \mathrm{Cl}$ & $P$-value & OR & $95 \% \mathrm{Cl}$ & $P$-value \\
\hline Vomiting & 1.02 & $0.40-2.63$ & 0.96 & 5.47 & $0.85-34.8$ & 0.07 & 1.21 & $0.63-2.35$ & 0.56 \\
\hline Nausea & 4.33 & $1.65-11.3$ & 0.003 & 3.30 & $0.39-28.1$ & 0.27 & 1.94 & $1.04-3.60$ & 0.04 \\
\hline Vomiting/nausea ${ }^{\mathrm{b}}$ & & & 0.008 & & & $<0.001$ & & & 0.004 \\
\hline Abdominal pain & 4.77 & $2.09-10.9$ & $<0.001$ & 0.77 & $0.21-2.88$ & 0.70 & 1.70 & $1.06-2.73$ & 0.03 \\
\hline Urgency & 1.53 & $0.70-1.83$ & 0.29 & 1.21 & $0.34-4.24$ & 0.77 & 1.14 & $0.7 I-1.83$ & 0.59 \\
\hline Gas & 2.30 & $1.03-5.10$ & 0.04 & 1.03 & $0.30-3.58$ & 0.96 & 1.55 & $0.97-2.49$ & 0.07 \\
\hline Winter season diagnosis & 2.30 & $1.0-4.82$ & 0.03 & 1.29 & $0.36-4.60$ & 0.69 & 1.07 & $0.65-1.77$ & 0.78 \\
\hline Chronic condition history & 1.34 & $0.4 I-4.35$ & 0.62 & 0.78 & $0.15-4.1$ & 0.76 & 0.90 & $0.48-1.67$ & 0.73 \\
\hline Follow-up visit number & 1.71 & $0.78-3.73$ & 0.18 & 1.63 & $0.49-5.44$ & 0.42 & 1.81 & $0.96-3.40$ & 0.07 \\
\hline Use of feeding tube & 1.08 & $0.46-2.57$ & 0.86 & 0.33 & $0.04 I-2.70$ & 0.30 & 0.85 & $0.49-1.48$ & 0.56 \\
\hline Antibiotic use in past 7 days & 2.07 & $0.70-6.16$ & 0.19 & $\mathrm{I} .44$ & $0.29-7.29$ & 0.66 & 2.89 & $1.47-5.69$ & 0.002 \\
\hline
\end{tabular}

Notes: andividuals without norovirus or $C$. difficile infection constituted the reference category. All ORs were adjusted for age, sex, and repeated sample collection after 2 weeks. ${ }^{\mathrm{b}}$ The interaction term for nausea and vomiting. A $P$-value of $<0.05$ was considered significant.

Abbreviations: $\mathrm{Cl}$, confidence interval; OR, odds ratio. 


\section{Discussion}

The aim of this study was to determine the prevalence of $C$. difficile and $\mathrm{HuNoV}$ coinfection in order to aid in clinical diagnosis, patient management, and infection control in the future. Our comprehensive analysis of coinfection with $\mathrm{HuNoV}$ and $C$. difficile in adult hospitalized patients indicated that coinfections with these two pathogens occur relatively frequently in this patient population. Our findings further indicate that patients with CDI experiencing nausea with or without vomiting, abdominal pain, and/or gas have a greater likelihood of being coinfected with HuNoV, especially during the winter season.

Several main conclusions can be drawn from the data presented in this study. First, our study confirmed findings from previous studies regarding the occurrence of coinfections of $C$. difficile and HuNoV. Previous studies in a pediatric population reported coinfection rates that ranged from $13 \%$ to $17 \%,{ }^{16,18}$ while $13 \%$ coinfection rates were reported in hospital-acquired CDI, ${ }^{30}$ and $16 \%$ in a long-term care facility. ${ }^{17}$ Using a next-generation sequencing approach, an $18 \%$ coinfection rate $(4 / 22)$ was detected..$^{31}$ The prevalence of coinfection in our cohort of 384 samples was $10 \%$. These slightly higher rates in previous studies may be due to a variety of reasons, such as smaller sample sizes, children being more likely to have asymptomatic $C$. difficile colonization in the intestinal tract, ${ }^{5}$ increased person-to-person transmission within long-term care facilities due to close proximity, or because we included a threshold for $\mathrm{HuNoV}$ positivity in our study.

The overall finding of coinfection raises the question regarding changes in disease severity in $C$. difficile- or HuNoV-infected patients compared with those coinfected with both pathogens. The second finding from our study was that patients with coinfection showed the highest mean number of follow-up visits compared with the other groups, consistent with the idea that concurrent pathogen infection may cause more severe disease outcomes than infection by either pathogen alone. Therefore, data presented herein indicate that the two pathogens may work synergistically when infecting concurrently to yield an intensified clinical impact in the host.

Third, our data demonstrated that the symptomatology of coinfections is not necessarily a combination of symptoms experienced with infection by a single pathogen. Vomiting is a well-characterized symptom during $\mathrm{HuNoV}$ infection. ${ }^{32}$ However, vomiting is not a feature of CDI and no association with vomiting was seen in $C$. difficile-infected patients in our study. Interestingly, no association between vomiting and coinfection was observed. Instead, coinfection of $C$. difficile and $\mathrm{HuNoV}$ was associated with nausea, abdominal pain, and gas, symptoms more frequently experienced by patients infected with $C$. difficile. These data indicate that symptoms caused by CDI may be dominant over HuNoV-induced symptoms in the setting of coinfection. Thus, in clinical settings, it may be beneficial (eg, for infection control or patient management) to take into account that patients who are diagnosed with CDI and present the symptoms of abdominal pain, gas, and nausea with or without vomiting may also be coinfected with $\mathrm{HuNoV}$. This would be particularly important during the winter season because our findings also suggest that the season of diagnosis can impact the likelihood of coinfection in patients as the incidence of coinfection was significantly higher during the winter months. HuNoV infections often peak in the winter months in the Northern Hemisphere. ${ }^{33,34}$ In contrast, CDI does not show seasonality trends because CDI rates are largely a result of antibiotics use. ${ }^{5}$ Therefore, the overall greater prevalence of $\mathrm{HuNoV}$ in the population during the winter months likely resulted in the greater odds of coinfection during winter that we observed in this study.

The current study also has certain limitations. One was the use of storage buffer for fecal samples. Transport of stool samples containing enteric bacterial pathogens often uses Cary Blair media $(\mathrm{pH}>8),{ }^{35}$ and it was used in our study. However, HuNoVs are inactivated by alkaline $\mathrm{pH} .{ }^{36} \mathrm{At} \mathrm{pH} 8$, increased solvent exposure of tyrosine residues and secondary structure changes were observed, resulting in reversible dissociation of the viral capsid. Thus, the $\mathrm{pH}$ of the Cary Blair buffer was not optimal for viral transport/storage and may have resulted in degradation of viral particles over time and a loss of HuNoV titers in the sample. This most likely explains our low sequencing success rate since samples were sequenced several years after collection and repeated freeze/ thaw events. Therefore, it is also unlikely that the $\mathrm{HuNoV}$ genome titers measured reflect accurately the viral titers at the time of collection. Furthermore, the inadequate storage buffer may have resulted in an underreporting of $\mathrm{HuNoV}$ infections, particularly since we utilized a threshold for HuNoV titers to prevent false-positive classification. Therefore, for any future studies of viral and bacterial coinfection, fresh, unmodified samples should be collected. Alternatively, parallel stool aliquots may be collected in viral as well as bacterial transport media.

Though our study design has limitations, the results may provide important guidelines for clinical practice and infection prevention. The identification of $\mathrm{HuNoV}$ in patients originally diagnosed to only have CDI is crucial 
in the clinical setting due to the highly contagious nature of the virus, where as little as $18 \mathrm{HuNoV}$ particles were estimated to be sufficient to cause an infection. ${ }^{37}$ Additionally, HuNoV shedding for weeks to months after the resolution of symptoms makes these viruses a key pathogen to be regulated by infection control in acute care settings. ${ }^{38}$ In addition, while limited studies have identified $\mathrm{HuNoV} /$ CDI coinfection in hospitalized and long-term care facility patients, our study serves as the first comprehensive analysis of coinfection with these two pathogens in adult hospitalized patients. This increased knowledge about the potential burden of coinfection in patients with gastrointestinal symptoms in clinical settings may result in improved diagnostic procedures.

In summary, we confirmed previous studies that coinfections of $\mathrm{HuNoV}$ and $C$. difficile occur in adult patients presenting clinical symptoms of gastroenteritis. Our study revealed that patients with coinfection are more likely to experience certain gastrointestinal symptoms - abdominal pain, gas, and nausea with or without vomiting - and show increased numbers of follow-up visits, suggesting direct or indirect interactions between these pathogens in the host during infection. These findings are consistent with an increased severity of disease in coinfected individuals but future studies are needed to identify the underlying mechanisms of pathogen interactions within the host, or whether the order of pathogen acquisition dictates patient outcomes. Regardless, clinicians diagnosing patients with CDI should be aware of possible $\mathrm{HuNoV}$ coinfections and the consequences for clinical treatment and infection prevention management.

\section{Acknowledgments}

This project was funded by the National Institutes of Health Enterics Research Investigational Network (ERIN) award \#AI090871 and supported by the University of Michigan Health System. The authors would like to thank Dr K. Green (National Institutes of Health, Bethesda, MD, USA) for her kind gift of the plasmid encoding the full-length clone of HuNoV MD145-12. Stefan Taube's current affiliation is: University of Lübeck, Institute for Virology and Cell Biology, Building 62, Ratzeburger Allee 160, D-23562 Lübeck, Germany.

\section{Disclosure}

The authors report no conflicts of interest in this work.

\section{References}

1. Hall AJ, Wikswo ME, Manikonda K, Roberts VA, Yoder JS, Gould LH. Acute gastroenteritis surveillance through the National Outbreak Reporting System, United States. Emer Infect Dis. 2013;19:1305-1309.

2. Black RE, Cousens S, Johnson HL, et al. Global, regional, and national causes of child mortality in 2008: a systematic analysis. Lancet. 2010;375:1969-1987.

3. Hall AJ, Curns AT, McDonald LC, Parashar UD, Lopman BA. The roles of Clostridium difficile and norovirus among gastroenteritis-associated deaths in the United States, 1999-2007. Clin Infect Dis. 2012;55: 216-223.

4. Dubberke E. Clostridium difficile infection: the scope of the problem J Hosp Med. 2012;7 Suppl 3:S1-4.

5. Britton RA, Young VB. Role of the intestinal microbiota in resistance to colonization by Clostridium difficile. Gastroenterology. 2014;146:1547-1553.

6. Ahmed SM, Hall AJ, Robinson AE, et al. Global prevalence of norovirus in cases of gastroenteritis: a systematic review and meta-analysis. Lancet Infect Dis. 2014;14:725-730.

7. Hall AJ, Lopman BA, Payne DC, et al. Norovirus disease in the United States. Emerg Infect Dis. 2013;19:1198-1205.

8. Scallan E, Hoekstra RM, Angulo FJ, et al. Foodborne illness acquired in the United States - major pathogens. Emerg Infect Dis. 2011;17: 7-15.

9. Scharff RL. Health Related Costs from Foodborne Illness in the United States. Washington DC: Georgetown University; 2010.

10. Vinje J. Advances in laboratory methods for detection and typing of norovirus. J Clin Microbiol. 2015;53(2):373-381.

11. Vega E, Barclay L, Gregoricus N, Shirley SH, Lee D, Vinje J. Genotypic and epidemiologic trends of norovirus outbreaks in the United States, 2009 to 2013. J Clin Microbiol. 2014;52:147-155.

12. Chan MC, Lee N, Hung TN, et al. Rapid emergence and predominance of a broadly recognizing and fast-evolving norovirus GII.17 variant in late 2014. Nat Commun. 2015;6:10061.

13. Atmar RL, Estes MK. The epidemiologic and clinical importance of norovirus infection. Gastroenterol Clin North Am. 2006;35: 275-290.

14. Lopman B, Gastañaduy P, Park GW, Hall AJ, Parashar UD, Vinjé J. Environmental transmission of norovirus gastroenteritis. Curr Opin Virol. 2012;2:96-102.

15. Rocha-Pereira J, Neyts J, Jochmans D. Norovirus: targets and tools in antiviral drug discovery. Biochem Pharmacol. 2014;91:1-11.

16. El Feghaly RE, Stauber JL, Tarr PI, Haslam DB. Viral co-infections are common and are associated with higher bacterial burden in children with Clostridium difficile infection. J Pediatr Gastroenterol Nutr. 2013;57:813-816.

17. Ludwig A, Sato K, Schirmer P, et al. Concurrent outbreaks with coinfection of norovirus and Clostridium difficile in a long-term-care facility. Epidemiol Infect. 2013;141:1598-1603.

18. Stockmann C, Rogatcheva M, Harrel B, et al. How well does physician selection of microbiologic tests identify Clostridium difficile and other pathogens in paediatric diarrhoea? Insights using multiplex PCR-based detection. Clin Microbiol Infect. 2015;21:179 e9-15.

19. Cunha BA, Thekkel V, Eisenstein L. Community-acquired norovirus diarrhoea outbreak mimicking a community-acquired $C$. difficile diarrhoea outbreak. J Hosp Infect. 2008;70:98-100.

20. Rogers MA, Greene MT, Young VB, et al. Depression, antidepressant medications, and risk of Clostridium difficile infection. BMC Med. 2013;11:121.

21. Walk ST, Micic D, Jain R, et al. Clostridium difficile ribotype does not predict severe infection. Clin Infect Dis. 2012;55:1661-1668.

22. Hoehne M, Schreier E. Detection of Norovirus genogroup I and II by multiplex real-time RT-PCR using a 3'-minor groove binder-DNA probe. BMC Infect Dis. 2006;6:69. 
23. Vinje J, Hamidjaja RA, Sobsey MD. Development and application of a capsid VP1 (region D) based reverse transcription PCR assay for genotyping of genogroup I and II noroviruses. JVirol Methods. 2004;116:109-117.

24. Bernard H, Hohne M, Niendorf S, Altmann D, Stark K. Epidemiology of norovirus gastroenteritis in Germany 2001-2009: eight seasons of routine surveillance. Epidemiol Infect. 2014;142:63-74.

25. Oh DY, Gaedicke G, Schreier E. Viral agents of acute gastroenteritis in German children: prevalence and molecular diversity. J Med Virol. 2003;71:82-93.

26. Hall TA. BioEdit. A user-friendly biological sequence alignment editor and analysis program for Windows 95/98/NT. Nucl Acids Symp Ser. 1999;41:95-98.

27. Thompson JD, Higgins DG, Gibson TJ. CLUSTAL W: improving the sensitivity of progressive multiple sequence alignment through sequence weighting, position-specific gap penalties and weight matrix choice. Nucleic Acids Res. 1994;22:4673-4680.

28. Felsenstein J. PHYLIP - Phylogeny Inference Package (Version 3.2). Cladistics. 1989;5:164-166.

29. Trang NV, Choisy M, Nakagomi T, Chinh NT. Determination of cut-off cycle threshold values in routine RT-PCR assays to assist differential diagnosis of norovirus in children hospitalized for acute gastroenteritis. Epidemiol Infect. 2015;143:3292-3299.

30. Taori SK, Wroe A, Hardie A, Gibb AP, Poxton IR. A prospective study of community-associated Clostridium difficile infections: the role of antibiotics and co-infections. J Infect. 2014;69:134-144.
31. Zhou Y, Wylie K, Ei Feghaly RE, et al. Metagenomic approach for identification of the pathogens associated with diarrhea in stool specimens. J Clin Microbiol. 2016;54(2):368-375.

32. Makison Booth C. Vomiting Larry: a simulated vomiting system for assessing environmental contamination from projectile vomiting related to norovirus infection. J Infect Prev. 2014;15:176-180.

33. Lopman B, Armstrong B, Atchison C, Gray JJ. Host, weather and virological factors drive norovirus epidemiology: time-series analysis of laboratory surveillance data in England and Wales. PLoS One. 2009; 4:e6671.

34. Colas de la Noue A, Estienney M, Aho S, et al. Absolute humidity influences the seasonal persistence and infectivity of human norovirus. Appl Environ Microbiol. 2014;80:7196-7205.

35. Brown NA, Lebar WD, Young CL, Hankerd RE, Newton DW. Diagnosis of Clostridium difficile infection: comparison of four methods on specimens collected in Cary-Blair transport medium and tcdB PCR on fresh versus frozen samples. Infect Dis Rep. 2011;3:e5.

36. Ausar SF, Foubert TR, Hudson MH, Vedvick TS, Middaugh CR. Conformational stability and disassembly of Norwalk virus-like particles. Effect of pH and temperature. J Biol Chem. 2006;281: 19478-19488.

37. Teunis PF, Moe CL, Liu P, et al. Norwalk virus: how infectious is it? $J$ Med Virol. 2008;80:1468-1476.

38. Barclay L, Park GW, Vega E, et al. Infection control for norovirus. Clin Microbiol Infect. 2014;20:731-740.
Clinical Epidemiology

\section{Publish your work in this journal}

Clinical Epidemiology is an international, peer-reviewed, open access, online journal focusing on disease and drug epidemiology, identification of risk factors and screening procedures to develop optimal preventative initiatives and programs. Specific topics include: diagnosis, prognosis, treatment, screening, prevention, risk factor modification,

Submit your manuscript here: https://www.dovepress.com/clinical-epidemiology-journa

\section{Dovepress}

systematic reviews, risk and safety of medical interventions, epidemiology and biostatistical methods, and evaluation of guidelines, translational medicine, health policies and economic evaluations. The manuscript management system is completely online and includes a very quick and fair peer-review system, which is all easy to use. 